\title{
Voice perturbations under the stress overload in young individuals: phenotyping and suboptimal health as predictors for cascading pathologies
}

\author{
A. Kunin ${ }^{1} \cdot$ N. Sargheini ${ }^{2} \cdot$ C. Birkenbihl ${ }^{3,4} \cdot$ N. Moiseeva ${ }^{1} \cdot$ Holger Fröhlich $^{3,4} \cdot$ Olga Golubnitschaja $^{5}$
}

Received: 26 October 2020 / Accepted: 30 October 2020 / Published online: 12 November 2020

(C) The Author(s) 2020

\begin{abstract}
Verbal communication is one of the most sophisticated human motor skills reflecting both - the mental and physical health of an individual. Voice parameters and quality changes are usually secondary towards functional and/or structural laryngological alterations under specific systemic processes, syndrome and pathologies. These include but are not restricted to dry mouth and Sicca syndromes, body dehydration, hormonal alterations linked to pubertal, menopausal, and andropausal status, respiratory disorders, gastrointestinal reflux, autoimmune diseases, endocrinologic disorders, underweight versus overweight and obesity, and diabetes mellitus. On the other hand, it is well-established that stress overload is a significant risk factor of cascading pathologies, including but not restricted to neurodegenerative and psychiatric disorders, diabetes mellitus, cardiovascular disease, stroke, and cancers. Our current study revealed voice perturbations under the stress overload as a potentially useful biomarker to identify individuals in suboptimal health conditions who might be strongly predisposed to associated pathologies. Contextually, extended surveys applied in the population might be useful to identify, for example, persons at high risk for respiratory complications under pandemic conditions such as COVID-19. Symptoms of dry mouth syndrome, disturbed microcirculation, altered sense regulation, shifted circadian rhythm, and low BMI were positively associated with voice perturbations under the stress overload. Their functional interrelationships and relevance for cascading associated pathologies are presented in the article. Automated analysis of voice recordings via artificial intelligence (AI) has a potential to derive digital biomarkers. Further, predictive machine learning models should be developed that allows for detecting a suboptimal health condition based on voice recordings, ideally in an automated manner using derived digital biomarkers. Follow-up stratification and monitoring of individuals in suboptimal health conditions are recommended using disease-specific cell-free nucleic acids (ccfDNA, ctDNA, mtDNA, miRNA) combined with metabolic patterns detected in body fluids. Application of the cost-effective targeted prevention within the phase of reversible health damage is recommended based on the individualised patient profiling.
\end{abstract}

Keywords Predictive preventive personalised medicine $\cdot$ Voice perturbation $\cdot$ Suboptimal health $\cdot$ Stress, survey $\cdot$ Primary vascular dysregulation · Vasospasm · Biomarker pattern · Individualised patient profile · Phenotyping · Flammer syndrome Body mass index $\cdot$ Underweight $\cdot$ Dry mouth syndrome $\cdot$ Hyposalivation $\cdot$ Xerostomia $\cdot$ Sicca syndrome $\cdot$ High altitude sickness $\cdot$ Tinnitus $\cdot$ Sense regulation $\cdot$ Pain sensitivity $\cdot$ Exercise-induced hypoalgesia $\cdot$ Microcirculation $\cdot$ Thirst $\cdot$ Circadian

A. Kunin, N. Sargheini and C. Birkenbihl contributed equally to this work.

Holger Fröhlich

holger.froehlich@scai.fraunhofer.de

Olga Golubnitschaja

Olga.Golubnitschaja@ukbonn.de

1 Departments of Maxillofacial Surgery and Hospital Dentistry, Voronezh N.N. Burdenko State Medical University,

Voronezh, Russia

2 Center of Molecular Biotechnology, CEMBIO, Friedrich-Wilhelms-Universität Bonn, Bonn, Germany
3 Department of Bioinformatics, Fraunhofer Institute for Algorithms and Scientific Computing (SCAI), Schloss Birlinghoven, 53757 Sankt Augustin, Germany

4 Bonn-Aachen International Center for IT, Rheinische Friedrich-Wilhelms-Universität Bonn, 53115 Bonn, Germany

5 Predictive, Preventive and Personalised (3P) Medicine, Department of Radiation Oncology, University Hospital Bonn, Friedrich-Wilhelms-Universität Bonn, Bonn, Germany 
rhythm · Otorhinolaryngologoical disorders · Disease predisposition · Machine learning models $\cdot$ Association $\cdot$ Risk factors · COVID-19 - Respiratory complications · Population screening · Pandemic $\cdot$ Risk assessment $\cdot$ Lifestyle intervention . Healthcare $\cdot$ Artificial intelligence $(\mathrm{AI})$

\section{Introduction}

\section{Human voice reflects both-mental and physical health of individuals}

Verbal communication is one of the most sophisticated human motor skills. Hundreds of muscles, innervated by a different network of the cranial and spinal nerve, subcortical, and cortical parts of the brain are involved in the production and processing of voice [1]. Contextually, the human voice is a complex phenomenon reflecting both-the mental and physical health of an individual [2]. According to the American Academy of Otolaryngology-Head and Neck Surgery Foundation, voice perturbations are defined as any abnormalities in the vocal quality, pitch, loudness, and vocal effort that influence communication or generate a negative effect on the voice-related quality of life $[3,4]$. Table 1 exemplifies bothphysiological and pathological factors associated with the voice perturbation.

Voice disturbances impact one in thirteen adults annually. According to the US National Ambulatory Medical Care Survey, almost $52 \%$ of adults revealed a voice problem that lasted more than a week [6]. Voice disturbances are among the most critical job-related hazards resulting from numerous vocal cord traumas among people who use their voice professionally, like teachers, singers, actors, telemarketers, salespersons, and nurses [7]. Among teachers in different parts of the world, the prevalence of voice disorders ranges from 20 to $80 \%$, and the most usual symptoms include dry throat, hoarseness, and throat clearing [8]. A high number of individuals with vocal perturbations do not consult a physician because their experienced symptoms are impermanent, and the condition is considered unimportant [9]. Consequently, early disease stages remain clinically undetected.

\section{Health conditions and disorders with the laryngeal manifestation}

Voice parameters and quality changes are usually secondary towards functional and/or structural laryngological alterations under certain systemic processes, syndrome, and pathologies. These include but are not restricted to Sicca syndrome [10], dry mouth syndrome [11] and body dehydration [12], hormonal alterations linked to pubertal [13], menopausal [14] and andropausal [15] status and acromegaly [16], cardiovocal syndrome [17], respiratory disorders (e.g. chronic obstructive pulmonary disease [18] and asthma [19]), gastrointestinal reflux [20], autoimmune diseases such as rheumatic arthritis [21] and Sjögren's syndrome [22], systemic lupus erythematosus [23], amyloidosis [24], cystic fibrosis [25], endocrinologic disorders such thyroid dysfunction $[26,27]$ and anorexia nervosa [28-30], underweight versus overweight and obesity [31, 32], and diabetes [33]. Table 2 highlights corresponding laryngeal symptoms.

\section{Voice as an indicator of the stress overload}

It is well-established that stress overload or imbalanced stress (i.e. highly increased stress load combined with insufficient repair capacity) is a significant risk factor of cascading pathologies, including but not restricted to neurodegenerative and psychiatric disorders, cancer, diabetes mellitus, cardiovascular disease, and stroke [34]. Unfortunately, there is an evident lack of reliable measurables and standardised approaches to estimate stress overload at the individual level. Indeed, a survey performed amongst college students revealed vocal fatigue significantly increased for individuals suffering from psychological stress [35]. Furthermore, anxiety has been demonstrated as affecting acoustic parameters of voice [36], and
Table 1 Physiological and pathological factors associated with the voice perturbation and disorders; information is modified from [5]

\begin{tabular}{|c|c|c|}
\hline Factors & Prevalence & $\begin{array}{l}\text { Literature } \\
\text { source }\end{array}$ \\
\hline Gender & - Higher prevalence of voice disorders in women & 6 \\
\hline Ageing & - Increasing prevalence of laryngeal disorders in elderly ( $>65$ years old) & 7 \\
\hline Puberty & - Prevalent alterations in voice parameters such as voice pitch & 8 \\
\hline $\begin{array}{r}\text { Family history of } \\
\text { voice disorders }\end{array}$ & $\begin{array}{l}\text { - Prevalent family history of hoarseness and voice disorders studied in } \\
\text { certain professional groups such as teachers }(P=0.0001)\end{array}$ & 9 \\
\hline $\begin{array}{l}\text { Professional } \\
\text { occupation }\end{array}$ & $\begin{array}{l}\text { - Voice perturbation and disorders are more prevalent in certain } \\
\text { professional groups such as teachers, call centre workers and singers }\end{array}$ & 10 \\
\hline Toxic environment & $\begin{array}{l}\text { - Higher risk of voice perturbation and laryngeal disorder in (both active } \\
\text { and passive) tobacco smokers }\end{array}$ & 11,12 \\
\hline
\end{tabular}


Table 2 Laryngeal manifestations of systemic processes and pathologies; "+"means increased

\begin{tabular}{|c|c|c|c|c|c|c|c|}
\hline $\begin{array}{l}\text { Diseases } \\
\text { Laryngeal } \\
\text { manifestations }\end{array}$ & $\begin{array}{l}\text { Laryngopharyngeal } \\
\text { reflux diseases }\end{array}$ & $\begin{array}{l}\text { Autoimmune } \\
\text { diseases }\end{array}$ & $\begin{array}{l}\text { Respiratory diseases } \\
\text { (e.g. asthma } \\
\text { bronchial) }\end{array}$ & $\begin{array}{l}\text { Endocrine disorders (e.g. } \\
\text { anorexia nervosa, } \\
\text { hypothyroid) }\end{array}$ & $\begin{array}{l}\text { BMI } \\
\text { (overweight } \\
\text { and obesity) }\end{array}$ & $\begin{array}{l}\text { Neurological } \\
\text { diseases }\end{array}$ & $\begin{array}{l}\text { Systemic } \\
\text { dehydration }\end{array}$ \\
\hline Dry mouth & Unknown & + & + & + & + & + & + \\
\hline MPT & Short & Short & Short & Short & Short & Short & Short \\
\hline Shimmer & + & + & + & + & + & + & + \\
\hline Jitter & + & + & + & + & + & + & + \\
\hline Hoarseness & + & + & + & + & + & + & + \\
\hline Roughness & + & + & + & + & + & + & + \\
\hline
\end{tabular}

psychological stress is clearly associated with vocal symptoms amongst professors who reported elevated stress that they experienced during previously given lessons [37].

\section{Primary vascular dysregulation/vasospasm as the stress facilitator}

Vasospasm frequently caused by primary vascular dysregulation occurring even in adolescents and young adults carries a systemic character and plays a pivotal role in oxidative stress and cascading pathologies [38]. There are multifaceted risk factors including but not restricted to genetic predisposition and specific phenotypes such as Flammer syndrome (FS), which synergistically lead to the imbalance between strong vasoconstriction and insufficient vasodilation. Vasospastic reaction is particularly pronounced under specific stimuli such as the cold provocation, hormonal, and emotional stress [39]. Consequently, developed vasoconstriction carries a systemic character affecting both (cold) extremities and poor microcirculation in the life-important organs [40]. In turn, prolonged and frequent systemic hypoxia and ischemic lesions may lead to

- Endothelial dysfunction and cardiovascular disease CVD [41]

- Mitochondrial dysfunction [42]

- Chronic inflammation [43]

- Impaired healing [44]

- Autoimmune diseases [45]

- Stroke and other neurological disorders [46]

- Aggressive cancer subtypes and metastatic disease [47-49], amongst others.

\section{A link between vasospastic reaction and dry mouth syndrome}

The coincidence and a potential functional link between vasospastic reaction and dry mouth syndrome have recently been detailed for Sjögren syndrome with cascading pathologies such as chronic inflammation and cancer predisposition [45]. Follow-up studies performed on young and healthy individuals revealed a statistically significant positive association between dry mouth syndrome/hyposalivation and several symptoms characteristic for the FS phenotype, such as decreased feeling of thirst but strongly pronounced reaction towards stress and imbalanced vasoconstriction [11].

\section{Working hypothesis}

In the current study, we hypothesised that the voice perturbation under stress conditions might be positively associated with signs and symptoms of dry mouth syndrome and vascular dysregulation in otherwise healthy individuals. To verify the hypothesis, young individuals recruited for the study underwent a comprehensive survey based on questions relevant to dysregulation, phenotyping, dry mouth syndrome, and voice problems observed specifically under the stress overload.

\section{Materials and methods}

\section{Study design}

Altogether 200 students, 18-23 years of age, were recruited for this international study at the Voronezh N.N. Burdenko State Medical University, Voronezh, Russia. Gender status was not considered as stratification criteria in the design of the current study. Recruited participants were informed about the study's purposes, have signed corresponding consent, and filled in the questionnaire.

\section{Dry mouth syndrome/hyposalivation}

Dry mouth syndrome/hyposalivation was determined by the Bother xerostomia Index (BI) utilising a questionnaire of 10 issue-specific items [50]. 


\section{FS phenotype}

Vasospasm relevant FS phenotype was characterised earlier [51]. The FS related items applied to the actual study have been developed at the University Hospital Basel, Switzerland [52].

\section{Comprehensive survey: phenotyping, symptoms, and signs of disturbed microcirculation and dry mouth syndrome relevant for suboptimal health and associated pathologies}

Items used in the actual study utilised knowledge collected towards their functional interconnections as demonstrated in a series of previous publications:

- Individualised patient profiles-phenotyping and genotyping in the transitional phase between suboptimal health and disease $[47,53]$

- Dry mouth syndrome in young individuals - potentially cascading pathologies [11]

- Vaginal dryness and potential diseases [54]

- Sjögren and Sicca syndrome [45]

- Phenotyping to assess risks of "young" stroke [46]

- Phenotyping to assess risks of cancer and metastatic disease development [47-49].

\section{Statistical analysis}

To identify statistically significant associations between individual items used for the survey and the occurrence of voice problems, logistic regression was performed with objects representing the independent- and voice problems the dependent variables. The analysed data consisted of 200 participants, of which 45 (22.5\%) reported voice problems. By applying a Wald-Test, we determined significant associations to a confidence level of 95\% (i.e. $P$ values smaller than 0.05 were considered significant). Multiple testing correction was performed via the Benjamini and Hochberg method. Participant's age and gender were considered as covariates in the model such that statistical results are corrected for their potential influence on the outcome.

\section{Results}

Statistical evaluation of the survey revealed 45 individuals (out of altogether 200 study participants) presenting $22.5 \%$ of the entire study population, who reported voice perturbations under stress conditions. Table 3 summarises statistically relevant symptoms associated with the occurrence of vocal problems under stress conditions. The signs of reported regression coefficients indicate a positive or negative association. Corresponding items have been grouped into five categories, namely
1. Signs and symptoms of dry mouth syndrome

2. Signs and symptoms of disturbed microcirculation

3. Altered sense regulation and shifted circadian rhythm

4. body shape

5. Prevalence of acute and chronic otorhinolaryngological disorders.

Thereby, categories 3 and 4 collectively describe the phenotype, which was found to be characteristic for individuals with the voice perturbation under stress conditions, namely low BMI, altered sense regulation (including the reduced feeling of thirst), and shifted circadian rhythm.

From the entire spectrum of dry mouth symptoms and signs described in the literature [50], only two were positively associated with the target group. However, reduced feeling of thirst may potentially cascade body dehydration leading to dry mouth and Sicca syndromes as detailed earlier [11, 54].

The relevance of the disturbed microcirculation was strongly supported by the positive association of both - high altitude sickness and tinnitus demonstrated for the target group with high level of statistical significance.

Noteworthy, the prevalence of acute and chronic otorhinolaryngological disorders was negatively associated with the target group that demonstrates otorhinolaryngological disorders as irrelevant for the voice perturbation under stress conditions in the study population.

\section{Case reports}

\section{Case 1}

Nineteen-year-old female studying medicine, generally healthy; evident voice perturbation under the stress overload; particularly noticeable responses have been given towards following symptoms:

- Do not feel thirsty but dry mouth at night, waking up in the morning and during the day

- Evidently disturbed microcirculation (frequently observed cold extremities and dizziness)

- Circadian rhythms is shifted towards later hours in the night

- Sleep duration below 7 hours

- Evident skin blotches in stress situations

There are stroke cases and cases with aggressive metastatic cancers amongst relatives in the family.

\section{Case 2}

Twenty-one-year-old male studying medicine, generally healthy; evident voice perturbation under the stress overload; 
Table 3 Comparative presentation of factors and symptoms identified in the study population as being positively (positive regression coefficient) or negatively (negative regression coefficient -3.7 otorhinolaryngological disorders) associated with voice perturbations under stress conditions; standard error and statistical significance ( $P$ value) are noted for each item; $P \leq 0.05$ is considered significant

\begin{tabular}{lll}
\hline Items & $\begin{array}{l}\text { Regression coefficient (standard } \\
\text { error) }\end{array}$ & $P$ value \\
\hline Dry mouth syndrome & & \\
$\quad$ Feeling of dry mouth at night or getting up & $2.1(0.9)$ & $<0.05$ \\
Problems with food tasting & $7.8(3.0)$ & $<0.01$ \\
Disturbed microcirculation & & $<0.01$ \\
High altitude sickness & $2.2(0.8)$ & $<0.001$ \\
Tinnitus & $3.0(0.8)$ & $<0.05$ \\
Altered sense regulation and shifted circadian rhythm & $1.9(0.9)$ & $<0.001$ \\
Usually do not feel thirsty & $3.3(0.9)$ & $<0.01$ \\
Increased pain sensitivity & $2.5(0.8)$ & $<0.05$ \\
Circadian rhythm is shifted towards later hours in the & & $<0.01$ \\
$\quad$ night & $2.0(0.8)$ & \\
Body shape & &
\end{tabular}

particularly noticeable responses have been given towards following symptoms:

- Strongly reduced feeling of thirst

- Dizziness

- Frequent migraine with accompanying symptoms such as migraine with aura

- Tinnitus

- Evident skin blotches in stress situations

- Sleep duration below 7 hours

There are stroke cases amongst relatives in the family.

\section{Case 3}

Eighteen-year-old female studying medicine, generally healthy; evident voice perturbation under the stress overload; particularly noticeable responses have been given towards following symptoms:

- Strongly reduced feeling of thirst

- Dizziness

- Frequent headache

- Strongly pronounced pain sensitivity

- Tinnitus

- Evident skin blotches in stress situations

- Circadian rhythms is shifted towards later hours in the night

- Sleep duration below 7 hours

- Sicca syndrome

- Wound healing is impaired
There are stroke cases amongst relatives in the family.

\section{Case 4}

Twenty-year-old female studying medicine, generally healthy; evident voice perturbation under the stress overload; particularly noticeable responses have been given towards following symptoms:

- $\quad$ BMI $<20 \mathrm{~kg} / \mathrm{m}^{2}$

- Do not feel thirsty but dry mouth at night and waking up in the morning

- Evidently disturbed microcirculation (frequently observed cold extremities, dizziness, high altitude sickness)

- Frequent headache

- Tinnitus

- Circadian rhythms is shifted towards later hours in the night

- $\quad$ Sleep duration below 7 hours

- Wound healing is impaired

There are stroke cases amongst relatives in the family.

\section{Data interpretation}

\section{Imbalanced stress conditions: the mechanism of cascading pathologies}

Excessive release of reactive oxygen species (ROS) and reactive nitrogen species (RNS) have been identified as initiators, mediators, and regulators of cellular oxidative stress (OxiS). 
OxiS can damage almost any biomolecule, including chromosomal and mitochondrial DNA $[55,56]$. Oxidative damage plays a vital role in cascading pathologies, which include but are not restricted to CVD [57], neurodegeneration [58-60], stroke [46], diabetes mellitus with a broad spectrum of complications [61], and cancers [43, 62] such as castrationresistant prostate cancer (via the androgen receptor (AR) dependent pathway) [63] and triple-negative breast cancer with aggressive metastatic diseases and particularly poor outcomes $[47,49]$. To this end, both ROS and RNS can be carcinogenic by modifying the inflammatory status [43], influencing cellular lipid structures, angiogenesis, and antiapoptotic pathways, amongst others $[62,64]$.

\section{Stress overload negatively impacts microcirculation, hormonal profile, immune system, and mitochondrial function}

Stress overload and disturbed microcirculation-the vicious circle by reciprocity Any kind of stress, such as hormonal, psychological, and emotional, is known to cause vasoconstriction and disturbed microcirculation [65] leading, in turn, to systemic hypoxic-ischemic effects and extended oxidative stress [44, 66-68]. The reciprocity may result in a vicious circle increasing the extent of bothdisturbed microcirculation and stress overload [69], which synergistically cascade a number of related pathologies [46, 47, 49, 63, 67, 70-72].

Stress overload and disturbed microcirculation synergistically lead to mitochondrial dysfunction and uncontrolled increase in ROS production and suppressed energy supply Mitochondrial dysfunction can be caused by an extensive production of ROS resulting from synergistic effects of the stress overload and disturbed microcirculation [73] that is characteristic for ageing and related pathologies [74]. In turn, mitochondrial dysfunction leads to an uncontrolled increase in the ROS production and suppressed energy supply-both resulting in extended damage to life-important biomolecules such as chromosomal and mitochondrial DNA and diminished repair capacity as detailed in the literature [47]. Depending on the individual genetic setup and environmental risk factors, affected individuals are strongly predisposed to neurodegenerative pathologies such as Alzheimer's disease or cancers $[47,75]$.

Stress overload, disturbed microcirculation, and accelerated ageing Individuals extensively exposed to imbalanced stress are strongly predisposed to accelerated ageingcorresponding mechanisms have been described [76-78]. Consequently, affected systems are hormonal regulation and immune system - both involved in longevity versus ageing with cascading related pathologies [79-81].
Stress overload, disturbed microcirculation, and immune dysfunction Stress-induced immune dysfunction [82] is well described in the literature. Chronic inflammation is a significant characteristic of the stress overload and disturbed microcirculation [44]. Potential implication is relevant for inflamm-ageing, acute infectious diseases [83, 84], chronic impairments [45], healing processes [44], and immune dysregulation in cancers [85], amongst others.

\section{High altitude sickness and tinnitus are attributable to disturbed microcirculation}

High altitude sickness Individuals with disturbed microcirculation demonstrate a prolonged adaptation to the changing altitude and a tendency towards high altitude sickness [86]. To this end, increased baroreceptor sensitivity has been demonstrated in the context of compromised cerebral blood flow and predisposition to the ischemic stroke [46, 87].

Tinnitus Stress overload and vascular dysregulation of different origin plays the key role in pathogenesis of tinnitus [88]. Although corresponding pathomechanisms are still under-investigated, the evident relationship between vascular dysregulation and tinnitus is the reduced bioavailability of nitric oxide (NO) in vasospastic individuals. NO is reduced in the jugular vein of individuals with tinnitus, resulting in disruption of microcirculation in the ear [89].

\section{Pain sensitivity is related to the quality of microcirculation}

Although corresponding regulatory mechanisms are not yet detailed in the literature, acupuncture's effects demonstrate that pain sensation is reduced by improving microcirculation [90]. Further, regular physical exercises are useful for improving microcirculation used, for example, for early lifestyle interventions in children for primary prevention [91]. On the other hand, exercise-induced hypoalgesia (EIH) is a wellestablished phenomenon, specifically in pain-free individuals. EIH describes a decrease in pain sensitivity after an acute bout of exercise. EIH, as a pain modulation tool, has important implications in several medical areas [92, 93].

\section{Low BMI is relevant for cascading pathologies}

Although physiologic body mass index (BMI) is a highly individual parameter, there are clear indications provided in the literature that BMI below $24 \mathrm{~kg} / \mathrm{m}^{2}$ is relevant for an increased overall and cause-specific mortality as demonstrated, for example, by a population-based cohort study of 3.6 million adults in the UK [94]. A study focused on prostate cancer specific mortality and overall mortality concerning BMI demonstrated a statistically significant increased risk of 
prostate cancer specific mortality and overall mortality in the group with high BMI $\left(\geq 27.5 \mathrm{~kg} / \mathrm{m}^{2}\right)$ as well as in the group with low BMI $\left(<22.5 \mathrm{~kg} / \mathrm{m}^{2}\right)$ compared to the reference group (BMI $22.5-25 \mathrm{~kg} / \mathrm{m}^{2}$ ) [95]. Data collected from 22 clinical trials showed that BMI $\geq 25 \mathrm{~kg} / \mathrm{m}^{2}$ was associated with better overall survival amongst prostate cancer patients compared to those with BMI $<25 \mathrm{~kg} / \mathrm{m}^{2}$ [96]. Further, clear indication has been provided, demonstrating that underweight women (BMI $<20)$ are at a sufficiently higher risk for BC diagnosis and mortality compared to the standard range BMI $=20-25$ [97].

\section{Dry mouth syndrome and body dehydration are relevant for both-voice changes and associated pathologies}

Dry mouth syndrome can result from some pathophysiological conditions, like exposure to acute and chronic stress, eating disorders (such as anorexia nervosa), metabolic syndrome(s), Sjögren's and Sicca syndromes, and head/neck radiotherapy application. In turn, hyposalivation may predispose individuals to chronic oral pain, dental caries, taste changes, halitosis, voice and digestive disorders, and burning mouth syndrome $[11,98]$. Xerostomia may impact tissue viscosity of the vocal tract and oral mucosa and subsequently influence vocal function [12]. Roh et al. [99] demonstrated that voice range profiles of pitch and loudness reduced remarkably in individuals with xerostomia. Individuals with primary Sjögren's syndrome and dry mouth show significantly increased voice handicap index [10]. Systemic dehydration and surface dehydration on vocal folds surface have a detrimental impact on tissue viscosity and mucosal wave and contribute to vocal fatigue $[100,101]$.

\section{PM-related conclusions and expert recommendations}

The current study followed 3PM-related guidelines recommended by the European Association for Predictive, Preventive and Personalised Medicine [102]. In detail, the following 3PM strategies are recommended:

A. Voice perturbation under the stress overload is considered a potent biomarker for suboptimal health conditions being positively associated with symptoms of dry mouth syndrome, disturbed microcirculation, altered sense regulation, shifted circadian rhythm as well as BMI $<20 \mathrm{~kg} /$ $\mathrm{m}^{2}$. According to the currently available literature cited above, there are clear functional interrelationships, which, therefore, considered as being evidence-based. Relevant cascading pathologies include but are not restricted to Sicca syndrome and body dehydration, cardio-vascular and hormonal alterations, respiratory disorders, endocrinologic and autoimmune disorders, stroke, and cancers. Therefore, extended surveys applied in the population might be useful, for example, to identify persons at high risk for respiratory complications under pandemic conditions such as COVID-19.

B. In our study, voice was analysed via a classical surveybased approach. Automated analysis of voice recordings via artificial intelligence $(\mathrm{AI})$ has a potential to derive digital biomarkers, which are less subjective than questionnaires and can be assessed also in an outpatient situation (e.g. via telephone) [103]. Further, predictive machine learning models should be developed that allows for detecting a suboptimal health condition based on voice recordings, ideally in an automated manner using digital biomarkers.

C. Follow-up stratification and monitoring of individuals in suboptimal health conditions identified by specialised surveys under point $\mathrm{A}$ and/or by $\mathrm{AI}$ under point $\mathrm{B}$ are recommended utilising disease specific cell-free nucleic acids (cfDNA, ctDNA, mtDNA, miRNA) combined with metabolic patterns detected in body fluids [43, 104-106]. To this end, severely affected cells and tissues intrinsically secrete cell-free nucleic acids [106] such as mitochondrial DNA fragments [107]. It has been demonstrated that COVID-19 patients with increased levels of mtDNA are at elevated death risk, necessity of ICU care and intubation [107].

D. Application of the cost-effective targeted prevention within the phase of reversible health damage is recommended based on the individualised patient profile created and risk assessment recommended under points A, B, and $\mathrm{D}$. The most prominent examples for the targeted prevention against cancer development and progression have been recently published $[56,62,64]$.

Acknowledgments Authors thank European Association for Predictive, Preventive and Personalised Medicine, EPMA, Brussels, Belgium, for professional support in organising this multicentre study.

Authors' contributions Olga Golubnitschaja is the project coordinator who has created the main scientific ideas and hypotheses presented in the manuscript and comprehensive survey used in the study. Nafiseh Sargheini and Olga Golubnitschaja have drafted the manuscript. Anatolij Kunin has coordinated patient recruitment and primary data analysis performed in Russia. Natalia Moiseeva has collected data based on the survey conducted. Colin Birkenbihl has performed a complete statistical analysis. Nafiseh Sargheini, Colin Birkenbihl, and Olga Golubnitschaja have performed the data interpretation. Holger Fröhlich supervised the statistical analysis, critically read the manuscript and contributed to the final editing. All the authors have read and approved the final manuscript.

Funding Open Access funding enabled and organized by Projekt DEAL.

\section{Compliance with ethical standards}

All individuals involved in the study were informed about the purposes of the study and consequently have signed their "consent of the individual 
under investigation". All procedures involving human participants were performed with the permission of the Ethical Committee of the Voronezh N.N. Burdenko State Medical University, Voronezh, Russia, which are in accordance with the ethical standards of the institutional and/or national research committees and with the 1964 Helsinki declaration and its later amendments or comparable ethical standards.

Conflict of interest The authors declare that they have no competing interests.

Consent declaration All individuals involved in investigations have been informed about the purposes of the study and have signed their consent for publishing the data.

Individuals interviewed for creating the case reports have been informed about the purposes of the study and have signed their consent for publishing the data.

Abbreviations AI, artificial intelligence; AR, androgen receptor; $\mathrm{BMI}$, body mass index; ccfDNA, circulating cell-free DNA; ctDNA, circulating tumour DNA; CVD, cardiovascular disease; EIH, exercise-induced hypoalgesia; FS, Flammer syndrome; MPT, maximum phonation time; miRNA, microRNA; mtDNA, mitochondrial DNA; NO, nitric oxide; OxiS, oxidative stress; PPPM/3PM, predictive preventive personalised medicine; RNS, reactive nitrogen species; ROS, reactive oxygen species

Open Access This article is licensed under a Creative Commons Attribution 4.0 International License, which permits use, sharing, adaptation, distribution and reproduction in any medium or format, as long as you give appropriate credit to the original author(s) and the source, provide a link to the Creative Commons licence, and indicate if changes were made. The images or other third party material in this article are included in the article's Creative Commons licence, unless indicated otherwise in a credit line to the material. If material is not included in the article's Creative Commons licence and your intended use is not permitted by statutory regulation or exceeds the permitted use, you will need to obtain permission directly from the copyright holder. To view a copy of this licence, visit http://creativecommons.org/licenses/by/4.0/.

\section{References}

1. Van Puyvelde M, Neyt X, McGlone F, Pattyn N. Voice stress analysis: a new framework for voice and effort in human performance. Front Psychol. 2018;9:1994. https://doi.org/10.3389/fpsyg. 2018.01994.

2. Low DM, Bentley KH, Ghosh SS. Automated assessment of psychiatric disorders using speech: a systematic review. Laryngoscope Investig Otolaryngol. 2020;1:96-116. https://doi. org/10.1002/lio2.354.

3. Schwartz SR, Cohen SM, Dailey SH, Rosenfeld RM, Deutsch ES, Gillespie MB, et al. Clinical practice guideline: hoarseness (dysphonia). Otolaryngol Head Neck Surg. 2009;3:S1-S31. https:// doi.org/10.1016/j.otohns.

4. Behlau M, Madazio G, Oliveira G. Functional dysphonia: strategies to improve patient outcomes. Patient Relat Outcome Meas. 2015;6:243-53. https://doi.org/10.2147/PROM.S68631.

5. Sargheini N, Golubnitschaja O. Voice as a biomarker for early detection and prediction of related disorders. Abstract in Golubnitschaja et al. The 10th anniversary of the European Association for Predictive, Preventive and Personalised (3P) Medicine - EPMA World Congress Supplement 2020. EPMA J 2020. https://doi.org/10.1007/s13167-020-00206.
6. Marmor S, Horvath KJ, Lim KO, Misono S. Voice problems and depression among adults in the United States. Laryngoscope. 2016;8:1859-64. https://doi.org/10.1002/lary.25819.

7. Behlau M, Zambon F, Madazio G. Managing dysphonia in occupational voice users. Curr Opin Otolaryngol Head Neck Surg. 2014;3: 188-94. https://doi.org/10.1097/MOO.0000000000000047.

8. Andrade BM, Giannini SP, Duprat Ade C, Ferreira LP. Relationship between the presence of videolaryngoscopic signs suggestive of laryngopharyngeal reflux and voice disorders in teachers. Codas. 2016;0:0. https://doi.org/10.1590/2317-1782/ 20162015122.

9. Turley R, Cohen S. Impact of voice and swallowing problems in the elderly. Otolaryngol Head Neck Surg. 2009;140:33-6. https:// doi.org/10.1016/j.otohns.2008.10.010.

10. Kim SY, Lee J, Choi YS, Kim JW, Kwok SK, Park YH, et al. Do I sound dry? Comparative voice analysis of primary Sjögren's syndrome. Clin Exp Rheumatol. 2018;3:130-6.

11. Kunin A, Polivka J Jr, Moiseeva N, Golubnitschaja O. "Dry mouth" and "Flammer" syndromes-neglected risks in adolescents and new concepts by predictive, preventive and personalised approach. EPMA J. 2018;3:307-17. https://doi.org/10.1007/ s13167-018-0145-7.

12. Verdolini K, Min Y, Titze IR, Lemke J, Brown K, van Mersbergen $\mathrm{M}$, et al. Biological mechanisms underlying voice changes due to dehydration. J Speech Lang Hear Res. 2002;2: 268-81. https://doi.org/10.1044/1092-4388(2002/021.

13. KVSH K, Garg A, NSA C, Singh SP, Datta R. Voice and endocrinology. Indian J Endocrinol Metab. 2016;5:590-4. https://doi. org/10.4103/2230-8210.190523.

14. Hamdan AL, Ziade G, Tabet G, Btaiche R, Fakhri G, Yatim F, et al. Vocal symptoms and acoustic findings in menopausal women in comparison to pre-menopause women with body mass index as a confounding variable. J Menopausal Med. 2017;2:117-23. https://doi.org/10.6118/jmm.2017.23.2.117.

15. Lenell C, Sandage MJ, Johnson AM. A tutorial of the effects of sex hormones on laryngeal senescence and neuromuscular response to exercise. J Speech Lang Hear Res. 2019;3:602-10. https://doi.org/10.1044/2018_JSLHR-S-18-0179.

16. Aydin K, Turkyilmaz D, Ozturk B, Dagdelen S, Ozgen B, Unal F, et al. Voice characteristics of acromegaly. Eur Arch Otorhinolaryngol. 2013;4:1391-6. https://doi.org/10.1007/ s00405-013-2369-4.

17. Wu VCC, Chen CC, Hung KC, Chern MS, Wan YL, Tsai FC, et al. Reversal of hoarseness with recognition of Ortner syndrome in a patient with severe mitral regurgitation. J Cardiol Cases. 2013;2:e48-50. https://doi.org/10.1016/j.jccase.

18. Shastry A, Balasubramanium RK, Acharya PR. Voice analysis in individuals with chronic obstructive pulmonary disease. IJOPL. 2014;2:45-9. https://doi.org/10.1016/S2213-2600(13)70052-3.

19. De Blay F, Delmas C, Peri E, Velten M, Petit-Thomas J, Kuntz H, et al. Dysphonia in asthmatic women using inhaled corticosteroids: it is not only a laryngeal inflammation. Eur Respir J. 2016;60:PA4907. https://doi.org/10.1183/13993003.congress2016.PA4907.

20. Lechien JR, Saussez S, Harmegnies B, Finck C, Burns JA. Laryngopharyngeal reflux and voice disorders: a multifactorial model of etiology and pathophysiology. J Voice. 2017;6:73352. https://doi.org/10.1016/j.jvoice.2017.03.015.

21. Hamdan AL, Sarieddine D. Laryngeal manifestations of rheumatoid arthritis. Autoimmune Dis. 2013;2013:103081. https://doi. org/10.1155/2013/103081.

22. Pierce JL, Tanner K, Merrill RM, Miller KL, Ambati BK, Kendall KA, et al. Voice disorders in Sjögren's syndrome: prevalence and related risk factors. Laryngoscope. 2015;6:1385-92. https://doi. org/10.1002/lary.25112. 
23. De Macedo MSFC, Costa KM, da Silva Filho M. Voice disorder in systemic lupus erythematosus. PLoS One. 2017;4:e0175893. https://doi.org/10.1371/journal.pone.0175893.

24. Muneeb A, Gupta S. Isolated laryngeal amyloidosis mimicking laryngeal cancer. Cureus. 2018;8:e3106. https://doi.org/10.7759/ cureus.3106.

25. Willis J, Michael DD, Boyer H, Misono S. Prevalence and severity of dysphonia in patients with cystic fibrosis: a pilot study. Otolaryngol Head Neck Surg. 2015;1:88-93. https://doi.org/10. $1177 / 0194599815581832$.

26. Bone SL, Vertigan AE, Eisenberg RL. Auditory-perceptual voice characteristics in pre-operative patients undergoing thyroid or parathyroid surgery. Folia Phoniatr Logop. 2012;2:87-93. https://doi.org/10.1159/000335779.

27. Lee CY, Long KL, Eldridge RJ, Davenport DL, Sloan DA. Preoperative laryngoscopy in thyroid surgery: do patients' subjective voice complaints matter? Surgery. 2014;6:1477-82; discussion 1482-3. https://doi.org/10.1016/j.surg.2014.08.038.

28. Pugh M, Waller G. The anorexic voice and severity of eating pathology in anorexia nervosa. Int J Eat Disord. 2016;6:622-5. https://doi.org/10.1002/eat.22499.

29. Pugh M, Waller G. Understanding the 'anorexic voice' in anorexia nervosa. Clin Psychol Psychother. 2017;3:670-6. https://doi.org/ 10.1002/cpp.2034

30. Hormoz E, Pugh M, Waller G. Do eating disorder voice characteristics predict treatment outcomes in anorexia nervosa? A pilot study. Cogn Behav Ther. 2019;2:137-45. https://doi.org/10.1080/ 16506073.2018.1476581.

31. Souza LBR, Santos MMD. Body mass index and acoustic voice parameters: is there a relationship? Braz J Otorhinolaryngol. 2018;4:410-5. https://doi.org/10.1016/j.bjorl.2017.04.003.

32. Barsties B, Verfaillie R, Roy N, Maryn Y. Do body mass index and fat volume influence vocal quality, phonatory range, and aerodynamics in females? Codas. 2013;4:310-8. https://doi.org/10. 1590/s2317-17822013000400003.

33. Hamdan AL, Kurban Z, Azar ST. Prevalence of phonatory symptoms in patients with type 2 diabetes mellitus. Acta Diabetol. 2013;5:731-6. https://doi.org/10.1007/s00592-012-0392-3.

34. Epel ES, Crosswell AD, Mayer SE, Prather AA, Slavich GM, Puterman E, et al. More than a feeling: a unified view of stress measurement for population science. Front Neuroendocrinol. 2018;49:146-69. https://doi.org/10.1016/j.yfrne.2018.03.001.

35. Ferreira LP, Guerra JR, Loiola CM, Ghirardi AC. Relationship between vocal symptoms in college students and their possible causes. Int Arch Otorhinolaryngol. 2012;3:306-12. https://doi. org/10.7162/S1809-97772012000300002.

36. Özseven T, Dügenci M, Doruk A, Kahraman HI. Voice traces of anxiety: acoustic parameters affected by anxiety disorder. Arch Acoust. 2018;43:625-36. https://doi.org/10.24425/aoa.2018. 125156

37. Besser A, Lotem S, Zeigler-Hill V. Psychological stress and vocal symptoms among university professors in Israel: implications of the shift to online synchronous teaching during the COVID-19 pandemic. J Voice. 2020:S0892-1997(20)30190-9. https://doi. org/10.1016/j.jvoice.2020.05.028.

38. Golubnitschaja O. Flammer syndrome - from phenotype to associated pathologies, prediction, prevention and personalisation V.11, 2019, ISBN 978-3-030-13549-2 ISBN 978-3-030-13550-8 (eBook), https://doi.org/10.1007/978-3-030-13550-8.

39. Barthelmes J, Nagele MP, Ludovici V, Ruschitzka F, Sudano I, Flammer AJ. Endothelial dysfunction in cardiovascular disease and Flammer syndrome-similarities and differences. EPMA J. 2017;2:99-109. https://doi.org/10.1007/s13167-017-0099-1.

40. Alba BK, Castellani JW, Charkoudian N. Cold-induced cutaneous vasoconstriction in humans: function, dysfunction and the distinctly counterproductive. Exp Physiol. 2019;8:1202-14. https://doi.org/10.1113/EP087718.

41. Vanhoutte PM, Shimokawa H, Feletou M, Tang EH. Endothelial dysfunction and vascular disease - a 30th anniversary update. Acta Physiol (Oxf). 2017;1:22-96. https://doi.org/10.1111/apha.12646.

42. Ham PB, Raju R. Mitochondrial function in hypoxic ischemic injury and influence of aging. Prog Neurobiol. 2017;157:92116. https://doi.org/10.1016/j.pneurobio.2016.06.006.

43. Qian S, Golubnitschaja O, Zhan X. Chronic inflammation: key player and biomarker-set to predict and prevent cancer development and progression based on individualized patient profiles. EPMA J. 2019;4:365-81. https://doi.org/10.1007/s13167-01900194-X.

44. Avishai E, Yeghiazaryan K, Golubnitschaja O. Impaired wound healing: facts and hypotheses for multi-professional considerations in predictive, preventive and personalised medicine. EPMA J. 2017;1:23-33. https://doi.org/10.1007/s13167-0170081-y.

45. Baban B, Golubnitschaja O. The potential relationship between Flammer and Sjögren syndromes: the chime of dysfunction. EPMA J. 2017;4:333-8. https://doi.org/10.1007/s13167-0170107-5.

46. Polivka J Jr, Polivka J, Pesta M, Rohan V, Celedova L, Mahajani $\mathrm{S}$, et al. Risks associated with the stroke predisposition at young age: facts and hypotheses in light of individualized predictive and preventive approach. EPMA J. 2019;1:81-99. https://doi.org/10. 1007/s13167-019-00162-5.

47. Golubnitschaja O. Feeling cold and other underestimated symptoms in breast cancer: anecdotes or individual profiles for advanced patient stratification? EPMA J. 2017;1:17-22. https://doi. org/10.1007/s13167-017-0086-6.

48. Zubor P, Gondova A, Polivka J Jr, Kasajova P, Konieczka K, Danko J, et al. Breast cancer and Flammer syndrome: any symptoms in common for prediction, prevention and personalised medical approach? EPMA J. 2017;2:129-40. https://doi.org/10.1007/ s13167-017-0089-3.

49. Bubnov R, Polivka J Jr, Zubor P, Konieczka K, Golubnitschaja O. Pre-metastatic niches in breast cancer: are they created by or prior to the tumour onset? "Flammer Syndrome" relevance to address the question. EPMA J. 2017;2:141-57. https://doi.org/10.1007/ s13167-017-0092-8.

50. Challacombe SJ, Osailan SM, Proctor GB. (2015) Book-chapter "clinical scoring scales for assessment of dry mouth". In the book Dry mouth: a clinical guide on causes, effects and treatments, Ed: Guy Carpenter, Springer, ISBN 978-3-642-55153-6. https://doi org/10.1007/978-3-642-55154-3.

51. Konieczka K, Ritch R, Traverso CE, Kim DM, Kook MS, Gallino A, et al. Flammer syndrome. EPMA J. 2014;1:11. https://doi.org/ 10.1186/1878-5085-5-11.

52. Flammer Syndrome. 2020. Available from: http://www.flammersyndrome.ch/index.php?id=32.

53. Golubnitschaja O, Flammer J. Individualised patient profile: clinical utility of Flammer syndrome phenotype and general lessons for predictive, preventive and personalised medicine. EPMA J. 2018;1:15-20. https://doi.org/10.1007/s13167-018-0127-9.

54. Goncharenko V, Bubnov R, Polivka J Jr, Zubor P, Biringer K, Bielik T, et al. Vaginal dryness: individualised patient profiles, risks and mitigating measures. EPMA J. 2019;1:73-9. https:// doi.org/10.1007/s13167-019-00164-3.

55. Zarkovic N. Roles and functions of ROS and RNS in cellular physiology and pathology. Cells. 2020;3:767. https://doi.org/10. 3390/cells9030767.

56. Samec M, Liskova A, Koklesova L, Samuel SM, Zhai K, Buhrmann $\mathrm{C}$, et al. Flavonoids against the Warburg phenotype - concepts of predictive, preventive and personalised medicine to cut the Gordian knot of cancer cell metabolism. 
EPMA J. 2020;3:377-98. https://doi.org/10.1007/s13167-02000217-y.

57. Incalza MA, D'Oria R, Natalicchio A, Perrini S, Laviola L, Giorgino F. Oxidative stress and reactive oxygen species in endothelial dysfunction associated with cardiovascular and metabolic diseases. Vasc Pharmacol. 2018;100:1-19. https://doi.org/10. 1016/j.vph.2017.05.005.

58. Brown GC. The endotoxin hypothesis of neurodegeneration. J Neuroinflammation. 2019;1:180. https://doi.org/10.1186/s12974019-1564-7.

59. Lassmann H. Multiple sclerosis pathology. Cold Spring Harb Perspect Med. 2018;3:a028936. https://doi.org/10.1101/ cshperspect.a028936.

60. Golubnitschaja $\mathrm{O}$. The key role of multiomics in the predictive, preventive and personalised medical approach towards glaucoma management. Klin Monatsbl Augenheilkd. 2018;235:1-5. https:// doi.org/10.1055/s-0044-101164.

61. Duarte AA, Mohsin S, Golubnitschaja O. Diabetes care in figures: current pitfalls and future scenario. EPMA J. 2018;2:125-31. https://doi.org/10.1007/s13167-018-0133-y.

62. Koklesova L, Liskova A, Samec M, Qaradakhi T, Zulli A, Smejkal K, et al. Genoprotective activities of plant natural substances in cancer and chemopreventive strategies in context of 3P medicine. EPMA J. 2020;11:261-87. https://doi.org/10.1007/ s13167-020-00210-5.

63. Udensi UK, Tchounwou PB. Oxidative stress in prostate hyperplasia and carcinogenesis. J Exp Clin Cancer Res. 2016;1:139. https://doi.org/10.1186/s13046-016-0418-8.

64. Kucera R, Pecen L, Topolcan O, Dahal AR, Costigliola V, Frank $\mathrm{A}$, et al. Prostate cancer management: long-term beliefs, epidemic developments in the early twenty-first century and 3PM dimensional solutions. EPMA J. 2020;11:399-418. https://doi.org/10. 1007/s13167-020-00214-1.

65. Shah SM, Meadows JL, Burg MM, Pfau S, Soufer R. Effects of psychological stress on vascular physiology: beyond the current imaging signal. Curr Cardiol Rep. 2020;12:156. https://doi.org/10. 1007/s11886-020-01406-x.

66. Rodriguez PG, Felix FN, Woodley DT, Shim EK. The role of oxygen in wound healing: a review of the literature. Dermatol Surg. 2008;9:1159-69. https://doi.org/10.1111/j.1524-4725. 2008.34254.x.

67. Everson-Rose SA, Roetker NS, Lutsey PL, Kershaw KN, Longstreth WT Jr, Sacco RL. Chronic stress, depressive symptoms, anger, hostility, and risk of stroke and transient ischemic attack in the multi-ethnic study of atherosclerosis. Stroke. 2014;45:2318-23. https://doi.org/10.1161/STROKEAHA.114. 004815.

68. Avishai E, Golubnitschaja O. (2019) Book-chapter "Flammer syndrome in the context of healing impairments - facts and hypotheses for multi-professional consideration". In the book: Flammer Syndrome from phenotype to associated pathologies, prediction, prevention and personalisation, Ed: Olga Golubnitschaja, springer, ISBN 978-3-030-13549-2. https://doi.org/10.1007/978-3-03013550-8.

69. Siegrist J, Sies H. Disturbed redox homeostasis in oxidative distress: a molecular link from chronic psychosocial work stress to coronary heart disease? Circ Res. 2017;121:103-5. https://doi.org/ 10.1161/CIRCRESAHA.117.311182.

70. Rottenberg J, Yaroslavsky I, Carney RM, Freedland KE, George CJ, Baji I, et al. The association between major depressive disorder in childhood and risk factors for cardiovascular disease in adolescence. Psychosom Med. 2014;2:122-7. https://doi.org/10. 1097/PSY.0000000000000028.

71. Polivka J, Kralickova M, Polivka J, Kaiser C, Kuhn W, Golubnitschaja O. Mystery of the brain metastatic disease in breast cancer patients: improved patient stratification, disease prediction and targeted prevention on the horizon? EPMA J. 2017;8:119-27. https://doi.org/10.1007/s13167-017-0087-5.

72. Burrage E, Marshall KL, Santanam N, Chantler PD. Cerebrovascular dysfunction with stress and depression. Brain Circ. 2018;2:43-53. https://doi.org/10.4103/bc.bc 618 .

73. Zhou H, Toan S. Pathological roles of mitochondrial oxidative stress and mitochondrial dynamics in cardiac microvascular ischemia/reperfusion injury. Biomolecules. 2020;1:85. https:// doi.org/10.3390/biom10010085.

74. Promotion of oxidative stress is associated with mitochondrial dysfunction and muscle atrophy in aging mice. Geriatr Gerontol Int. 2020;1:78-84. https://doi.org/10.1111/ggi.13818.

75. Golubnitschaja $\mathrm{O}$, Costigliola V. Common origin but individual outcomes: time for new guidelines in personalised healthcare. Pers Med. 2010;5:561-8. https://doi.org/10.2217/pme.10.42.

76. Cao X, Jin X, Liu B. The involvement of stress granules in aging and aging-associated diseases. Aging Cell. 2020;4:e13136. https:// doi.org/10.1111/acel.13136.

77. Palma-Gudiel H, Fañanás L, Horvath S, Zannas AS. Psychosocial stress and epigenetic aging. Int Rev Neurobiol. 2020;150:107-28. https://doi.org/10.1016/bs.irn.2019.10.020.

78. Streese L, Khan AW, Deiseroth A, Hussain S, Suades R, Tiaden A, et al. Effects of psychological stress on vascular physiology: beyond the current imaging signal. Eur J Prev Cardiol. 2020;2: 168-76. https://doi.org/10.1177/2047487319880367.

79. Meldrum DR, Casper RF, Diez-Juan A, Simon C, Domar AD, Frydman R. Aging and the environment affect gamete and embryo potential: can we intervene? Fertil Steril. 2016;3:548-59. https:// doi.org/10.1016/j.fertnstert.2016.01.013.

80. Ruan H, Hu J, Zhao J, Tao H, Chi J, Niu X, et al. Menopause and frailty: a scoping review. Menopause. 2020;10:1185-95. https:// doi.org/10.1097/GME.0000000000001612.

81. Sampathkumar NK, Bravo JI, Chen Y, Danthi PS, Donahue EK, Lai RW, et al. Widespread sex dimorphism in aging and agerelated diseases. 2020;3:333-56. https://doi.org/10.1007/s00439019-02082-w.

82. Glaser R, Kiecolt-Glaser JK. Stress-induced immune dysfunction: implications for health. Nat Rev Immunol. 2005;3:243-51. https:// doi.org/10.1038/nri1571.

83. Bonafè M, Prattichizzo F, Giuliani A, Storci G, Sabbatinelli J, Olivieri F. Inflamm-aging: why older men are the most susceptible to SARS-CoV-2 complicated outcomes. Cytokine Growth Factor Rev. 2020;53:33-7. https://doi.org/10.1016/j.cytogfr.2020.04. 005.

84. Chaari L, Golubnitschaja O. Covid-19 pandemic by the "realtime" monitoring: the Tunisian case and lessons for global epidemics in the context of 3PM strategies. EPMA J. 2020;11:133-8. https://doi.org/10.1007/s13167-020-00207-0.

85. Zhang L, Pan J, Chen W, Jiang J, Huang J. Chronic stress-induced immune dysregulation in cancer: implications for initiation, progression, metastasis, and treatment. Am J Cancer Res. 2020;5: 1294-307.

86. Flammer J, Konieczka K, Flammer AJ. The primary vascular dysregulation syndrome: implications for eye diseases. EPMA J. 2013;1:14. https://doi.org/10.1186/1878-5085-4-14.

87. Donnelly J, Budohoski KP, Smielewski P, Czosnyka M. Regulation of the cerebral circulation: bedside assessment andclinical implications. Crit Care. 2016;20:129. https://doi.org/ 10.1186/s13054-016-1293-6.

88. Sabel BA, Wang J, Fähse S, Cárdenas-Morales L, Antal A. Personality and stress influence vision restoration and recovery in glaucoma and optic neuropathy following alternating current stimulation: implications for personalized neuromodulation and rehabilitation. EPMA J. 2020;2:177-96. https://doi.org/10.1007/ s13167-020-00204-3. 
89. Loiselle AR, Neustaeter A, de Kleine E, van Dijk P, Jansonius NM. Associations between tinnitus and glaucoma suggest a common mechanism: a clinical and population-based study. Hear Res. 2020;386:107862. https://doi.org/10.1016/j.heares.2019.107862.

90. Min S, Lee H, Kim SY, Park JY, Chae Y, Lee H, et al. Local changes in microcirculation and the analgesic effects of acupuncture: a laser Doppler perfusion imaging study. J Altern Complement Med. 2015;1:46-52. https://doi.org/10.1089/acm. 2013.0442.

91. Siegrist M, Hanssen H, Lammel C, Haller B, Koch AM, Stemp P, et al. Effects of a cluster-randomized school-based prevention program on physical activity and microvascular function (JuvenTUM 3). Atherosclerosis. 2018;278:73-81. https://doi.org/10.1016/j. atherosclerosis.2018.09.003.

92. Hughes L, Patterson SD. Low intensity blood flow restriction exercise: rationale for a hypoalgesia effect. Med Hypotheses. 2019;132:109370. https://doi.org/10.1016/j.mehy.2019.109370.

93. Rice D, Nijs J, Kosek E, Wideman T, Hasenbring MI, Koltyn K, et al. Exercise-induced hypoalgesia in pain-free and chronic pain populations: state of the art and future directions. J Pain. 2019;11: 1249-66. https://doi.org/10.1016/j.jpain.2019.03.005.

94. Bhaskaran K, Dos-Santos-Silva I, Leon DA, Douglas IJ, Smeeth L. Association of BMI with overall and cause-specific mortality: a population-based cohort study of 3.6 million adults in the UK. Lancet Diabetes Endocrinol. 2018;12:944-53. https://doi.org/10. 1016/S2213-8587(18)30288-2.

95. Greenlee H, Unger JM, LeBlanc M, Ramsey S, Hershman DL. Association between body mass index and cancer survival in a pooled analysis of 22 clinical trials. Cancer Epidemiol Biomarkers Prev. 2017;1:21-9. https://doi.org/10.1158/10559965.EPI-15-1336

96. Zhao J, Stockwell T, Roemer A, Chikritzhs T. Is alcohol consumption a risk factor for prostate cancer? A systematic review and meta-analysis. BMC Cancer. 2016;1:845. https://doi.org/10. 1186/s12885-016-2891-z.

97. Chan DSM, Vieira AR, Aune D, Bandera EV, Greenwood DC, McTiernan A, et al. Body mass index and survival in women with breast cancer-systematic literature review and meta-analysis of 82 follow-up studies. Ann Oncol. 2014;10:1901-14. https://doi.org/ 10.1093/annonc/mdu042.

98. Wu L, Zhang Z. A computational study of vocal fold dehydration during phonation. EEE Trans Biomed Eng. 2017;12:2938-48. https://doi.org/10.1109/TBME.2017.2691399.
99. Roh JL, Kim HS, Kim AY. The effect of acute xerostomia on vocal function. Arch Otolaryngol Head Neck Surg. 2006;5:542 6. https://doi.org/10.1001/archotol.132.5.542.

100. Sivasankar M, Leydon C. The role of hydration in vocal fold physiology. Curr Opin Otolaryngol Head Neck Surg. 2010;3: 171-5. https://doi.org/10.1097/MOO.0b013e3283393784.

101. Witt RE, Taylor LN, Regner MF, Jiang JJ. Effects of surface dehydration on mucosal wave amplitude and frequency in excised canine larynges. Otolaryngol Head Neck Surg. 2011;1:108-13. https://doi.org/10.1177/0194599810390893.

102. Golubnitschaja O, Baban B, Boniolo G, Wang W, Bubnov R, Kapalla M, et al. Medicine in the early twenty-first century: paradigm and anticipation - EPMA position paper 2016. EPMA J. 2016;1:23. https://doi.org/10.1186/s13167-016-0072-4.

103. Jeancolas L. Mangone G, Corvol J-C, Vidailhet M, Lehéricy S, Benkelfat B-E, Benal H, Petrovska-Delacrétaz D. Comparison of telephone recordings and professional microphone recordings for early detection of Parkinson's disease, using Mel-Frequency Cepstral Coefficients with Gaussian Mixture Models. Conference: Interspeech 2019. https://doi.org/10.21437/ interspeech.2019-2825.

104. Gerner C, Costigliola V, Golubnitschaja O. Multiomic patterns in body fluids: technological challenge with a great potential to implement the advanced paradigm of 3P medicine. Mass Spectrom Rev. 2020;5-6:442-51. https://doi.org/10.1002/mas.21612.

105. Stastny I, Dankova Z, Kajo K, Kubatka P, Golubnitschaja O, Zubor P. Aberrantly methylated cfDNA in body fluids as a promising diagnostic tool for early detection of breast cancer. Clin Breast Cancer. 2020;20:30111-7. https://doi.org/10.1016/j.clbc.

106. Torres Crigna A, Samec M, Koklesova L, Liskova A, Giordano FA, Kubatka P, et al. Cell-free nucleic acid patterns in disease prediction and monitoring - hype or hope? EPMA J. 2020. https://doi.org/10.1007/s13167-020-00226-x.

107. Scozzi D, Cano M, Ma L, Zhou D, Zhu JH, O’Halloran JA, Goss C, Rauseo AM, Liu Z, Peritore V, et al. Circulating mitochondrial DNA is an early indicator of severe illness and mortality from COVID-19. bioRxiv 2020, https://doi.org/10.1101/2020.07.30. 227553.

Publisher's note Springer Nature remains neutral with regard to jurisdictional claims in published maps and institutional affiliations. 